\title{
Microwave Class-E Power Amplifiers: A Brief Review of Essential Concepts in High-Frequency Class-E PAs and Related Circuits
}

\author{
Zoya Popović ${ }^{1}$ and José A. García ${ }^{2}$ \\ ${ }^{1}$ Department of Electrical, Computer and Energy Engineering, \\ University of Colorado, Boulder, CO, 80309, U.S.A. \\ ${ }^{2}$ Department of Communications Engineering, University of Cantabria, 39005 Santander, Spain
}

\section{Introduction: Frequency Scaling of the Class-E PoWer AMPlifier}

Since Nathan Sokal's invention of the class-E power amplifier (PA), the vast majority of class-E results have been reported at $\mathrm{kHz}$ and $\mathrm{MHz}$ frequencies, but the concept is increasingly applied in the UHF [1-13], microwave, e.g. [14-20], and even in the millimeter-wave range, e.g. [21]. The focus of this paper is a brief review of some interesting concepts in high-frequency class-E PAs and related circuits. The history of the development of class-E amplifiers at lower frequencies is overviewed elsewhere in this issue in the paper "History of the Development of Switching- Mode Class-E Technique for High-Efficiency Power Amplification” by A. Grebennikov and F. H. Raab.

Scaling class-E operation to higher frequencies presents a number of challenges. The most obvious is the maximum frequency of class-E operation derived for the ideal class-E circuit as:

$$
f_{\max , E} \cong I_{\max } /\left(56.5 C_{O U T} V_{d s}\right) \text {. }
$$

where $I_{\max }$ is the maximum drain-to-source current of the switching device and $V_{d s}$ its drain-tosource biasing voltage. The transistor output capacitance $C_{O U T}$ limits the frequency range of classE operation, as does the drain-to-source voltage which implies lower output power. COUT can be de-embedded from a nonlinear model or measured large-signal parameters and used as a part of the output matching circuit. The class-E mode of operation is defined by the time-domain waveforms for a 50\% duty cycle and assuming soft switching (both voltage and the derivative of 
the voltage are zero). Assuming a high-Q output circuit and ideal bias choke, the current and voltage waveforms across the transistor can be derived, and the Fourier expansion used to find the theoretical impedance at the fundamental frequency:

$$
Z_{E}=0.28 /\left(\omega C_{O U T}\right) e^{j 49^{\circ}}
$$

This expression obtained from idealized circuit assumptions is the impedance at the virtual drain (current source) of the transistor, and if this impedance is presented to a device, it will operate in class-E mode, at frequencies governed by Eqs. (1) and (2). Designing an output circuit with an impedance $Z_{E}$ at the switching frequency is a good starting point for design. The theory behind Eq. (2) assumes that all higher harmonics are open-circuited. At lower frequencies, this condition, along with a high-Q output circuit and a nearly ideal choke, can be implemented with lumped elements. However, in the UHF and microwave frequency range lumped elements often have parasitics that limit the Q-factor and are difficult to predict. On the other hand, distributed elements have lower loss and become sufficiently small. Fig. 1a shows a transmission-line implementation of a class-E PA with only the second harmonic termination [1]. The line and stub near the transistor output reference plane, at the current source, terminate the second harmonic in an open circuit, and together with the other two transmission lines present $Z_{E}$ from Eq.(2) at the fundamental frequency.

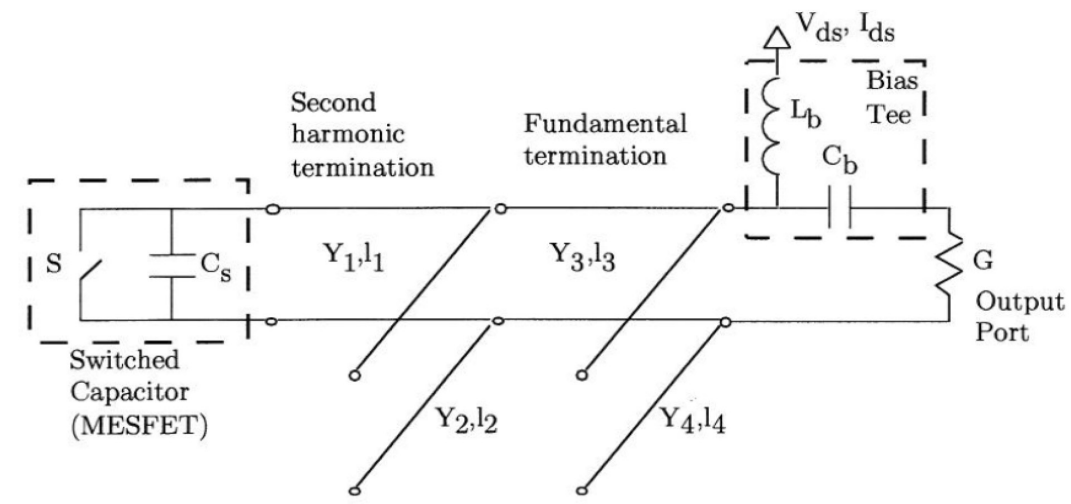

(a)

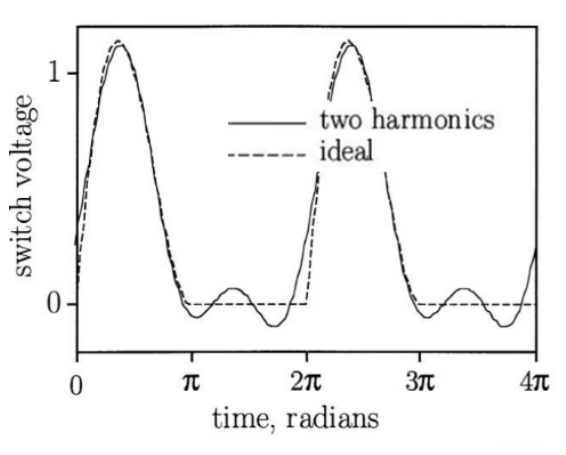

b)

Fig. 1. (a) Transmission-line circuit topology for high-frequency class-E PAs with only $2^{\text {nd }}$ harmonic opencircuited, and (b) associated switch voltage waveform degradation. 
Active device internal parasitics are substantial at high frequencies and difficult to de-embed from nonlinear models, so the design of class-E waveforms at the virtual drain, where they are specified, becomes a challenge. Additionally, the nonlinearity of the output capacitance affects the voltage and current time-domain waveforms, and increases the voltage or current stress on the device and lowers the output power, as shown in Fig.2 [14]. Another limitation is the device breakdown voltage, which needs to be at least 3.56 times the supply voltage for class-E operation, and therefore at high frequencies typically the output power is reduced. Design challenges also include input matching (switch control signal), bias line design, losses in the matching network and lowfrequency instabilities. Finally, the ideal class-E impedance given by Eq.(2) traces a counterclockwise loop on the Smith chart with increasing frequency, limiting the class-E operational bandwidth.

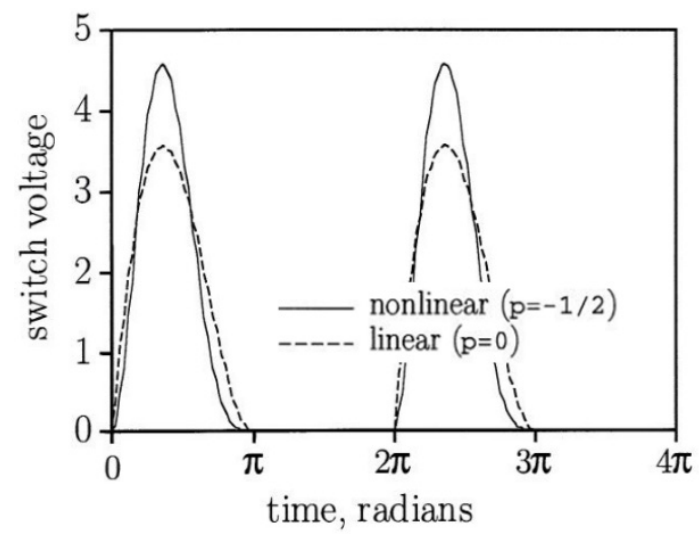

Fig. 2. When the device output capacitance is nonlinear $(p=-1 / 2$ is a square-root $C(V)$ nonlinearity), the voltage peak increases theoretically $28 \%$ for this simple nonlinearity [14]. The vertical axis assumes a $1-\mathrm{V}$ drain supply voltage, showing the increase of the peak compared to the $3.56 \mathrm{~V}_{\mathrm{D}}$ maximum swing for a linear output capacitance of the transistor CoUT.

\section{UHF CLASS-E PAS}

The standard series resonant circuit at the output of a class-E PA, as proposed by Sokal, requires a high loaded Q-factor, but at UHF and low microwave frequencies, the parasitics associated with a high inductance value may result in self-resonance below the most significant higher order harmonics, making proper harmonic terminations difficult [22]. A parallel resonant circuit, tuned to provide the open condition at the second, third harmonic or any convenient frequency between them, is shown in Fig. 3a and is discussed in [2]. A network that assures an impedance value closer 
to the optimum for both $2^{\text {nd }}$ and $3^{\text {rd }}$ harmonic implements the parallel resonance with the coil parasitic capacitance [3]. If the value is lowered below the one that self-resonates between $2 f$ and $3 f$, its resistive losses may be reduced. The resulting lower Q-factor at the fundamental widens the bandwidth, while the degradation in efficiency may be negligible as long as the impedance at the most relevant harmonics remains high enough. The output network is completed with a series reactance and a shunt capacitor to provide the optimum class-E termination at the fundamental. For the choke inductance $L_{b}$, a coil self-resonating at or near the fundamental may be selected and placed as in Fig. 3a to avoid any undesired perturbation over the synthesized reactive terminations at $2 f$ and $3 f$.

Alternative lumped-element implementations, e.g. [4], have been derived from the frequencydomain transmission-line synthesis approach illustrated in Fig.1. The use of coils and capacitors has been also reported at UHF for other topologies in the continuum of class-E modes. For any value of the dc-feed inductance $L_{b}$ in Fig. 3b, optimum real and imaginary parts of the impedance at the fundamental that satisfy zero-voltage and zero-voltage derivative switching (ZVS and ZVDS) conditions can be found [5] as a function of $q=1 / \sqrt{L_{b} \cdot C_{\text {out }}}$. Tracing a counterclockwise trajectory with frequency on a Smith chart, a simple $L C R$ series network, as the one in Fig. 3b, may be adjusted to intercept it at two points, with the frequency spacing defining the bandwidth versus efficiency tradeoff [6]. The parallel resonant circuit would in this case play the same function as described above.

The original series resonant topology is highly sensitive to load variations, and lumped-element networks that guarantee ZVS operation along a wide range of resistive loads have been proposed. In the UHF and low microwave bands, a few implementation solutions with load-insensitive operation has been demonstrated, based either on the addition of a transmission line equivalent network [7], or on the $q=1.3$ case [8] of the continuous class-E space described in [5]. In Fig. 3c, a slight modification to the topology in Fig. 3a based on pioneering work at low frequency MOSFET class-E inverters [23] is presented. An inductance to ground allows approximating the optimum trajectory for efficient load modulation [9]. 
a)

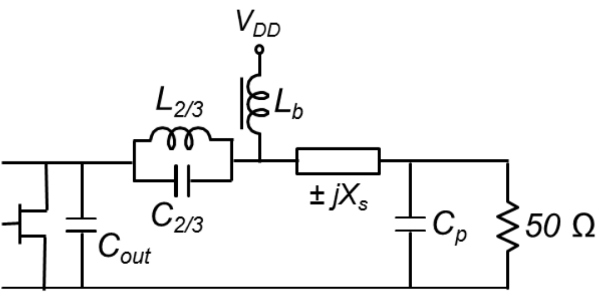

b)

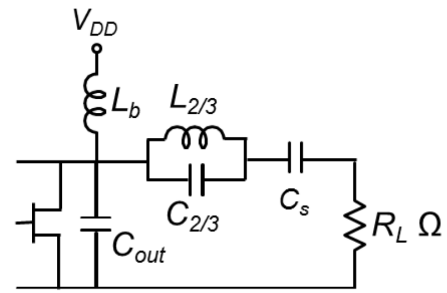

c)

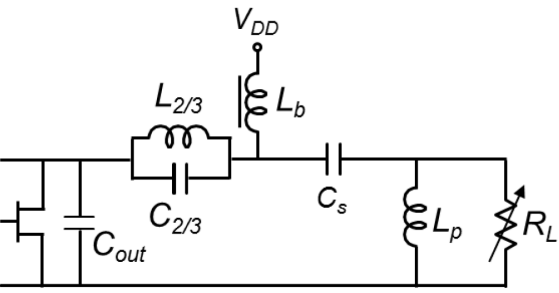

Fig. 3. Schematics of lumped-element topologies at UHF band: (a) wideband class-E PA; (b) continuousmode class-E PA; and (c) class-E PA for variable load operation.

Lumped-element UHF implementation examples of the above topologies are shown in Figs. 3, 4 and 5. All of them are based on the CGH35030F packaged GaN HEMT from Wolfspeed, using high-Q coils from the Air Core series (Coilcraft) and high Q multilayer capacitors from the 100B series (ATC). In the amplifier in Fig.3, the class-E operation is approximated over a wide bandwidth, trading resonant circuit Q-factors at the fundamental and $2^{\text {nd }} / 3^{\text {rd }}$ harmonics. A peak efficiency of $85.7 \%$ was measured, and maintained above $80 \%$ over a $230 \mathrm{MHz}$ frequency range (27\% fractional bandwidth) with $4.2 \mathrm{~dB}$ of output power variation.

The dc-feed inductance in the PA of Fig. 4 is carefully selected among commercially available values for continuous-mode class-E operation. The output capacitance of the CGH35030F transistor allows operation directly across a $50 \Omega$ load in the desired frequency band. The parallel resonant circuit for $2 f$ and $3 f$ terminations is provided by the parasitic capacitance of the coil in the output network. An efficiency value above $80 \%$ was measured for the $630-890 \mathrm{MHz}$ frequency range (34\% of fractional bandwidth) with a peak of $86.6 \%$. The output power variation in that range is only of $2.3 \mathrm{~dB}$. 


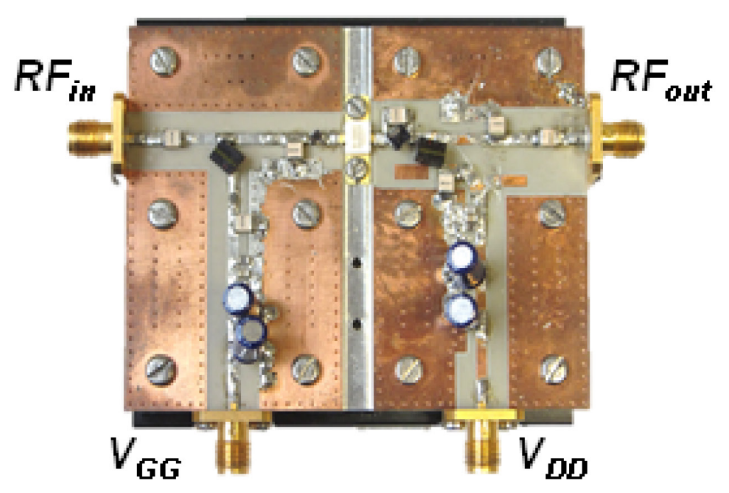

(a)
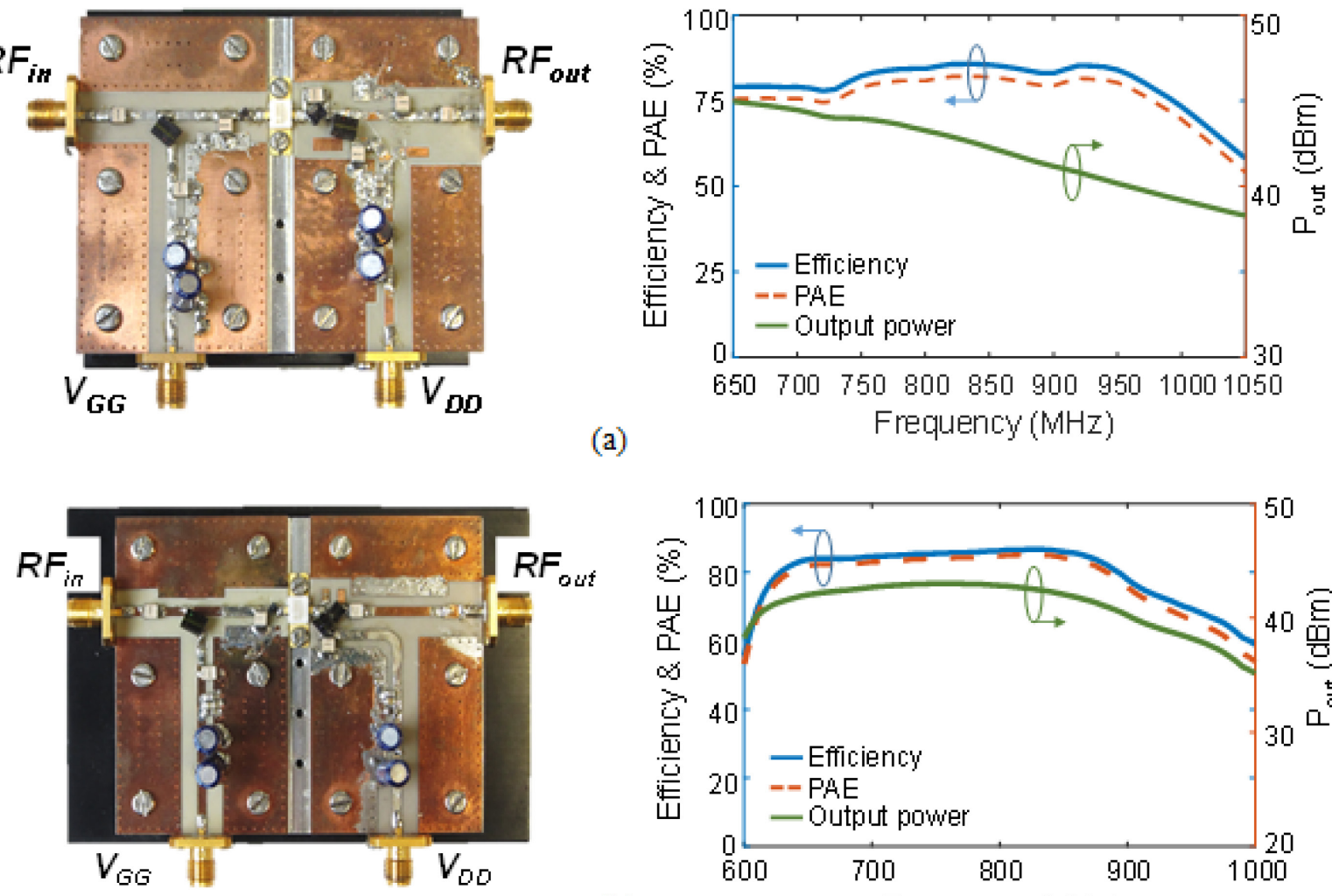

(b)

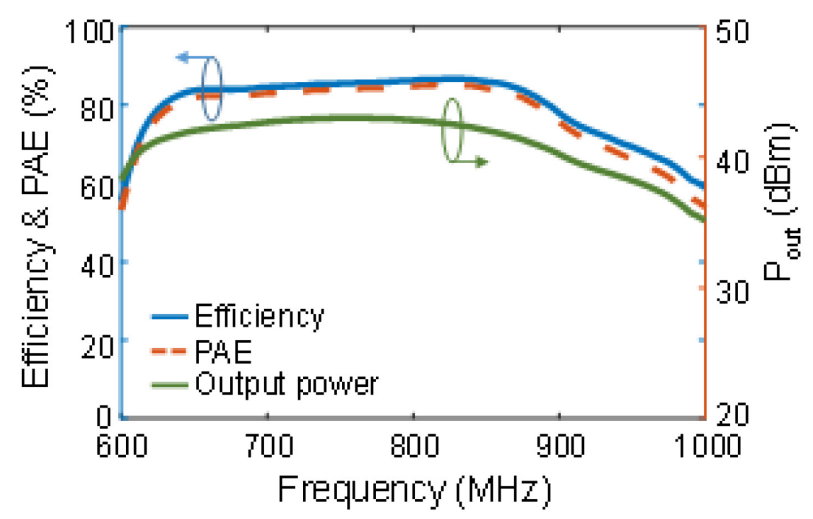

Fig.4. (a) Wideband lumped-element class-E PA in the 800-MHz UHF band, with measured frequency response [10]. (b) Wideband continuous-mode class-E PA and measured frequency response [6].

The amplifier in Fig. 5 follows the schematic in Fig. 3c for load-modulated but narrowband ZVS operation. With an $85 \%$ efficiency peak at $50 \Omega$ loading condition, the measured efficiency was still as high as $70 \%$ at $10 \mathrm{~dB}$ of power backoff.
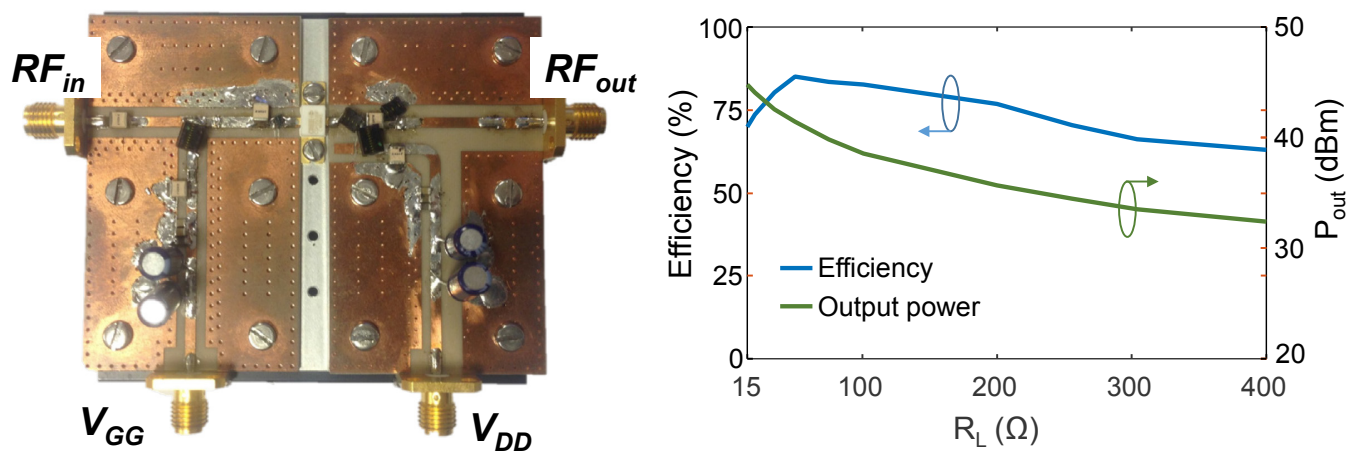

Fig. 5. Class-E PA for variable load operation with measured results versus loading resistance [9]. 
The first transmission-line implementations at $500 \mathrm{MHz}, 1 \mathrm{GHz}$ and $2 \mathrm{GHz}$ using a GaAs MESFET (CLY5) are shown in Fig.6 [1]. In this work, the theoretical degradation with increasing frequency for a given device is shown experimentally, and the circuits are designed analytically for first-pass success. Above $1 \mathrm{GHz}$, the device parameters do not satisfy Eq. (1) and the mode of operation first becomes a sub-optimal class-E mode, degrading into $\mathrm{AB}$ as the frequency increases further. The output power could not be well predicted due to the inadequacy of non-linear models in 1995.

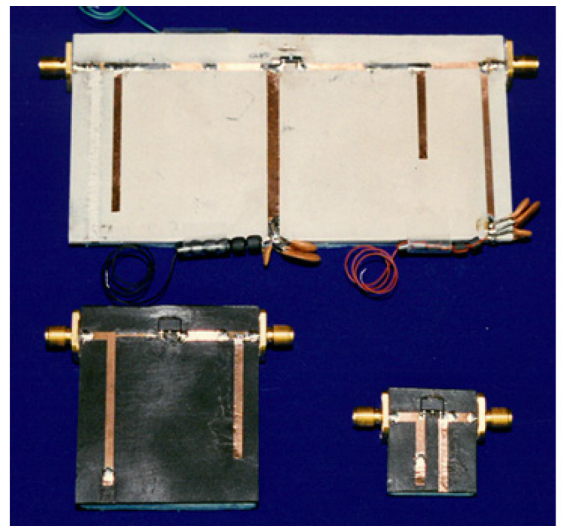

(a)

\begin{tabular}{|l|l|l|l|}
\hline Frequency & $0.5 \mathrm{GHz}$ & $1 \mathrm{GHz}$ & $2 \mathrm{GHz}$ \\
\hline Gain $_{\text {meas }}$ & $15.3 \mathrm{~dB}$ & $14.7 \mathrm{~dB}$ & $9.1 \mathrm{~dB}$ \\
\hline PAE $_{\text {meas }}$ & $80 \%$ & $73 \%$ & $54 \%$ \\
\hline$\eta_{\mathrm{D}, \text { theory }}$ & $85 \%$ & $73 \%$ & $56 \%$ \\
\hline$\eta_{\mathrm{D} \text {,meas }}$ & $83 \%$ & $75 \%$ & $62 \%$ \\
\hline $\mathrm{P}_{\text {OUT,theory }}$ & $0.77 \mathrm{~W}$ & $1.35 \mathrm{~W}$ & $2.07 \mathrm{~W}$ \\
\hline $\mathrm{P}_{\text {OUT,meas }}$ & $0.55 \mathrm{~W}$ & $0.94 \mathrm{~W}$ & $0.53 \mathrm{~W}$ \\
\hline
\end{tabular}

(b)

Fig. 6. (a) Photograph of first reported transmission-line 0.5, 1 and $2 \mathrm{GHz}$ class-E PAs implemented with the CLY5 GaAs MESFET [1]. (b) Summary of measured and theoretically predicted performance.

Transmission-line class-E amplifiers have also been implemented at lower UHF frequencies when high output power levels might exceed voltage/current handling of lumped components. A photograph of such a class-E PA is shown in Fig.7 [11]. The 370-MHz PA is designed around a GaN-on-SiC HEMT and delivers $65 \mathrm{~W}$ with $\mathrm{PAE}=82 \%$, and $45 \mathrm{~W}$ with $\mathrm{PAE}=84 \%$, with supply voltages of $35 \mathrm{~V}$ and $28 \mathrm{~V}$, respectively. Starting from class-E ideal impedance values, load-pull under Class-E conditions is used for device characterization and matching network design. A weighted Euclidean distance is defined to enable tradeoff studies between output power and efficiency to reach the final amplifier design [12]. 


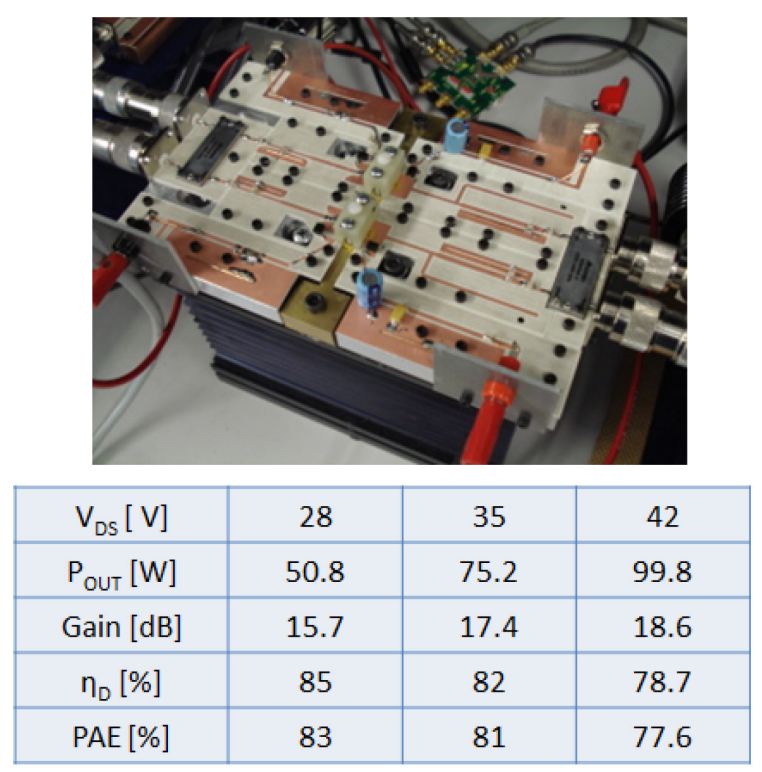

(a)

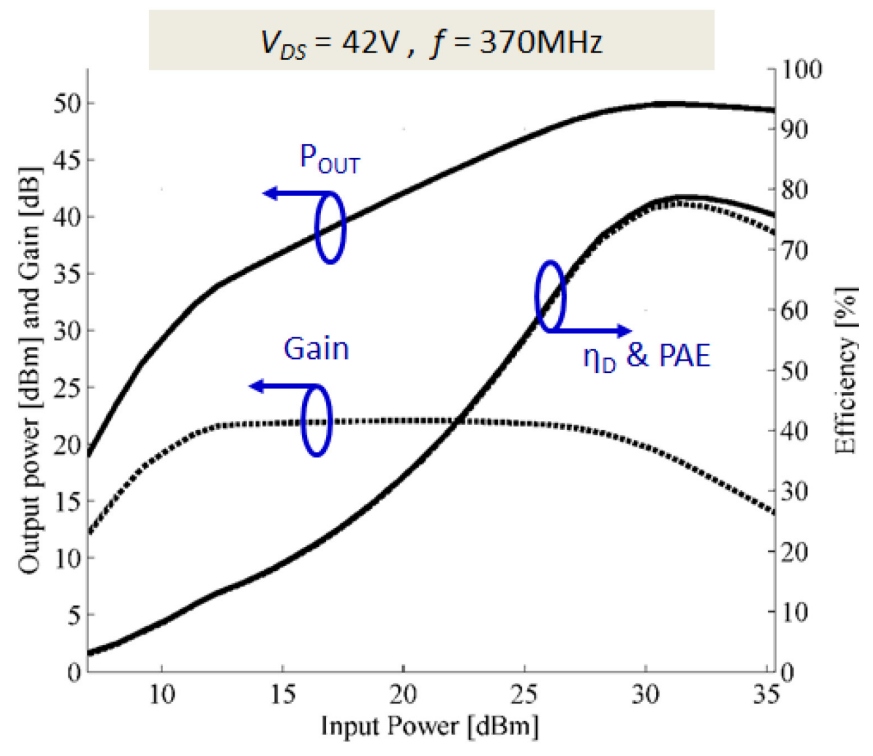

(b)

Fig.7. (a) Photo of 370-MHz hybrid class-E transmission-line PA with a GaN-on-SiC device from RFMD $\left(\mathrm{RF} 3934\right.$, rated at $48 \mathrm{~V}$ with $\left.\mathrm{C}_{\mathrm{OUT}}=18 \mathrm{pF}, \mathrm{R}_{\mathrm{ON}, \mathrm{DC}}=0.19 \Omega, \mathrm{V}_{\mathrm{TH}}=-4.2 \mathrm{~V}\right)$. Note the $\mathrm{N}$ connectors for size. The table shows performance versus supply voltage for Pin=31 dBm. (b) Measured amplifier CW performance at $42 \mathrm{~V}$ drain supply [11].

In [12], class-E UHF PAs using 4 different devices are compared: (1) Nitronex NPTB00050 (NITX050) GaN-on-Si HEMT (breakdown $V_{b r}=100 \mathrm{~V}, C_{\text {out }}=9$ pF); (2) RFMD RF3932 (RFM060) GaN-on-SiC HEMT ( $\left.V_{b r}=150 \mathrm{~V}, C_{\text {out }}=9 \mathrm{pF}\right)$; (3) Cree CRF24060 (CREE060) SiC MESFET $\left(V_{b r}\right.$ $\left.=120 \mathrm{~V}, C_{\text {out }}=11 \mathrm{pF}\right)$; and (4) Agere AGR09045E (LDMOS045) Si LDMOS $\left(V_{b r}=65 \mathrm{~V}, C_{\text {out }}=23\right.$ $\mathrm{pF}$ ). The PAs were all designed using as a starting point ideal class-E equations, and then a loadpull is performed to determine the power-efficiency tradeoff, Fig. 8 . The final results measured on all four PAs, including performance over supply voltage, are shown in Fig.8, demonstrating over $45 \mathrm{~W}$ and over $80 \%$ efficiency in all cases, with the GaN HEMT amplifiers showing best overall performance in the UHF range (2008). A detailed comparison in terms of design parameters, AM$\mathrm{AM}$ and AM-PM performance as well as performance over supply voltage is given in [12]. 


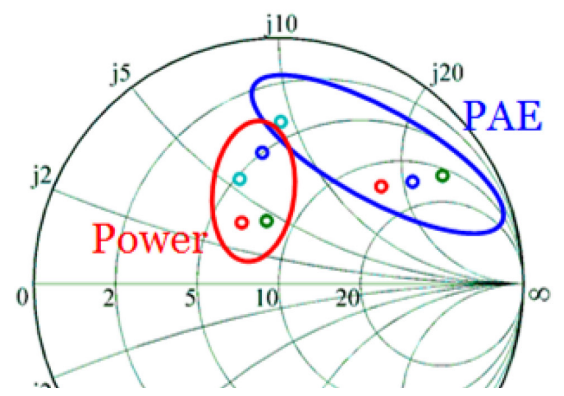

Load pull at $370 \mathrm{MHz}$

\begin{tabular}{|c|c|c|}
\hline Transistor & Optimum Pout & Optimum Efficiency \\
\hline NITX050 'o' & $63 \mathrm{~W}, 68 \% @ 5+j 7.5 \Omega$ & $30 \mathrm{~W}, 84 \% @ 14+j 22 \Omega$ \\
\hline RFMD060 'o' & $53 \mathrm{~W}, 75 \% @ 8+j 4.4 \Omega$ & $14 \mathrm{~W}, 93 \% @ 11.8+j 29 \Omega$ \\
\hline CREE060 'o' & $53 \mathrm{~W}, 70 \% @ 6.6+j 3.6 \Omega$ & $20 \mathrm{~W}, 89 \% @ 13.5+j 16 \Omega$ \\
\hline LDMOS045 'o' & $40 \mathrm{~W}, 74 \% @ 5.2+j 5.6 \Omega$ & $24 \mathrm{~W}, 82 \% @ 4+j 9.3 \Omega$ \\
\hline
\end{tabular}

(a)
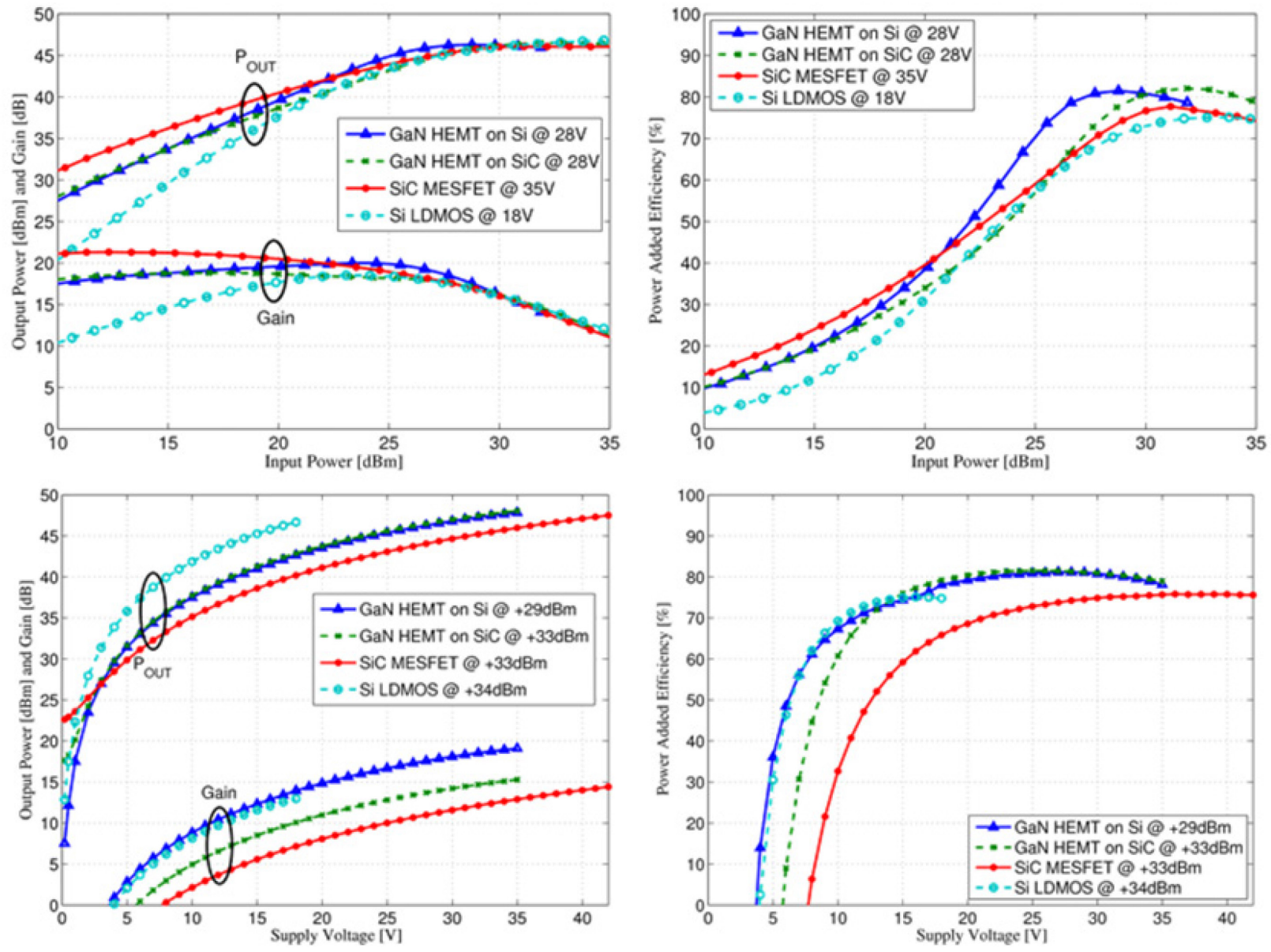

(b)

Fig.8. (a) Load-pull data showing maximum output power and PAE points for the 4 devices, along with the corresponding data shown in the table. (b) Measured performance of the 4 PAs implemented as hybrid transmission-line PAs [12]. 


\section{Microwave Class-E Amplifiers}

A discussion on frequency scaling related to class-E performance up to X-band is reviewed nicely in [13] and shown on GaAs MMIC and GaN hybrid example PAs. A number of hybrid class-E amplifiers were reported at C-band, e.g. [14] and X-band [15-20] with GaAs FETs. MMIC classE PAs are demonstrated in GaAs [13,15,20], InP [16], GaN [19] and CMOS/SiGe [21,24]. In 1998, a GaS MESFET (FLK052WG) class-E microstrip PA that delivers $0.61 \mathrm{~W}$ with a compressed gain of $9.8 \mathrm{~dB}$, a drain efficiency of $81 \%$, and a PAE of $72 \%$ at $5 \mathrm{GHz}$ was integrated in a spatial combining array [14]. Anti-resonant slot antennas were used to present the harmonic terminations. More recently, several X-band GaAs class-E PAs are demonstrated with PAE $>60 \%$, and an example is shown in Fig.9, where a class-E PA stage is incorporated into a two-stage PA with the first stage also operated in class-E mode, reaching a total PAE $=52 \%$ with the drain efficiency of the second stage of $62 \%$ [16].
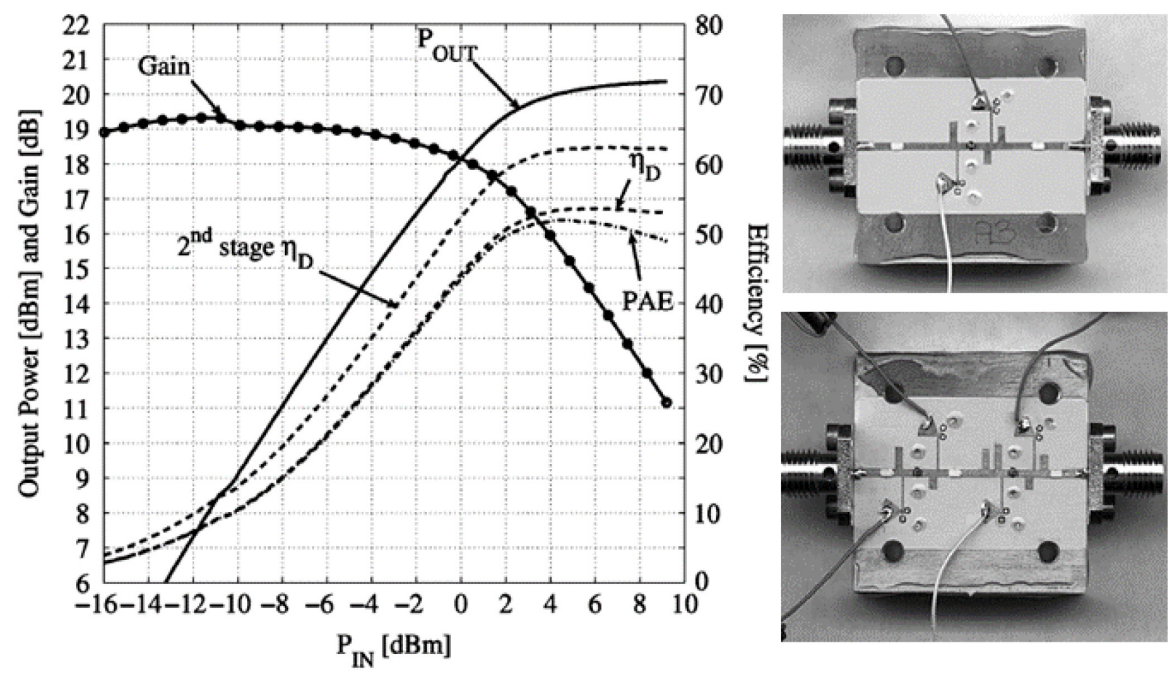

Fig. 9. Photograph of the output stage only (top right) of a hybrid class-E $10-\mathrm{GHz}$ GaAs PA with PAE=62\%, and a two-stage class-E PA with both stages operating close to the class-E condition (bottom). The plots show measured data for the two-stage PA calibrated at the SMA connectors [16].

Fig. 10 shows a reconfigurable 10-GHz PA with an output matching network which enables the PA to operate in either linear class-A/AB or high-efficiency class-E using two Sandia MEMS ohmic switches. The insertion loss of the matching network in different states is below $0.3 \mathrm{~dB}$, 
causing a few points degradation in PAE compared to a non-reconfigurable static PA made on the same alumina substrate and with the same GaAs MESFET die [18].

(a)
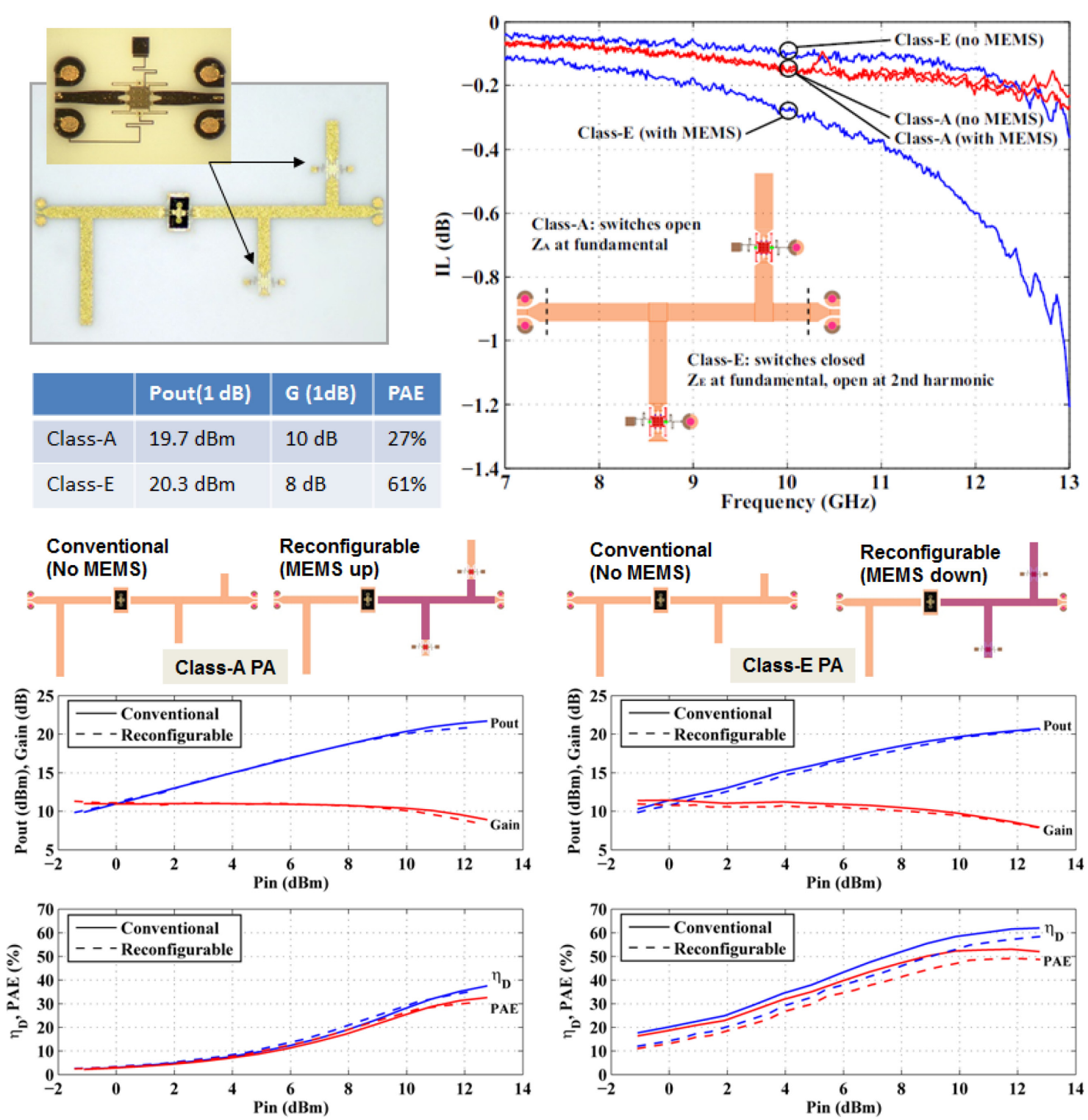

(b)

Fig. 10. (a) Photo of reconfigurable class-A/E PA with two MEMS switches [18]. The plot shows measured insertion loss of the matching networks with a degradation due to reconfigurability of at most $0.2 \mathrm{~dB}$ at 10 GHz. (b) Measured data in class-A (left) and class-E (right) modes for the 10-GHz mode-reconfigurable PA. The dashed lines show efficiency loss due to the reconfigurable MEMS network by comparing to a static class-E PA. 
One of the first reported GaAs class-E X-band PAs is discussed in [15] and a photograph of the single-stage MMIC and its measured performance is shown in Fig. 11, showing $\mathrm{PAE}=65 \%$ at a power of $24 \mathrm{dBm}$. MMIC integrated class-E PAs at X-band include an InP two-stage amplifier shown in Fig. 12 [16], which had a measured PAE=52\% and compared well with the hybrid GaAs version in [16] in terms of efficiency points lost due to the first stage. In the case of two-stage class-E PAs [17], the interstage network can be designed to provide input harmonic wave-shaping for a more squared waveform that controls the transistor operating as a switch. More recently, several silicon-based lower-power class-E PAs have been reported, where stacking of devices is used to overcome the breakdown voltage limitation. In [24], a $\mathrm{SiGe} \mathrm{PA}$ at 2.3-2.4 GHz demonstrated 62-65\% efficiency using on-chip lumped elements, while in [25] 5.3-GHz CMOS class-E PA showed $\mathrm{PAE}=42 \%$ with a power density of $532 \mathrm{~mW} / \mathrm{mm}^{2}$. Other class-E PAs demonstrated in silicon at lower microwave frequencies are shown in, e.g. [26] - [32], with up to $1 \mathrm{~W}$ of output power level in the $1-2 \mathrm{GHz}$ range. The millimeter-wave PA described in [21] demonstrates a CMOS IC at $93 \mathrm{GHz}$ with PAE $>40 \%$, showing that Sokal's class-E concept can be extended to extremely high frequencies, Fig. 13.

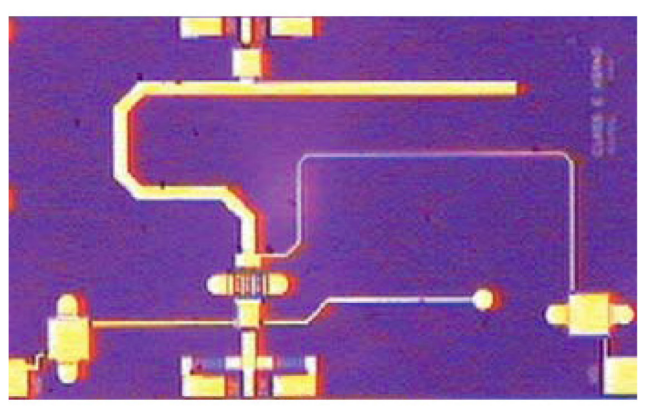

$1.5 \mathrm{~mm} \times 0.6 \mathrm{~mm}$ GaN MMIC

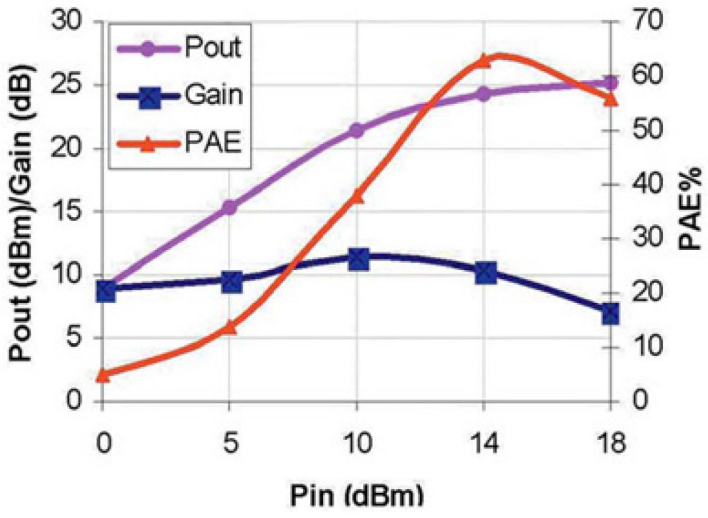

Pin $(\mathrm{dBm})$

Fig. 11. GaAs MMIC PA from [15] measured at $10.6 \mathrm{GHz}$. 

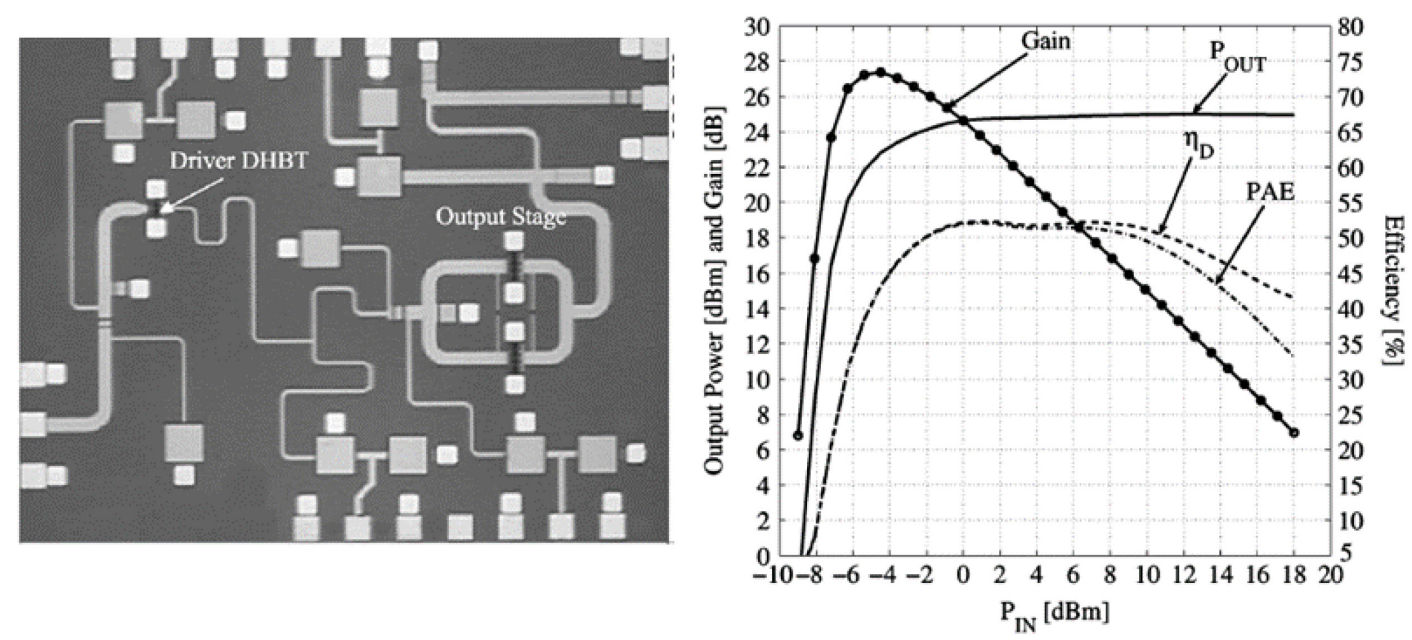

Fig. 12. InP two-stage PA MMIC photo (left) and measured performance (right) [16]. The MMIC is 2.65 $\mathrm{mm} \times 2.1 \mathrm{~mm}$ in size.
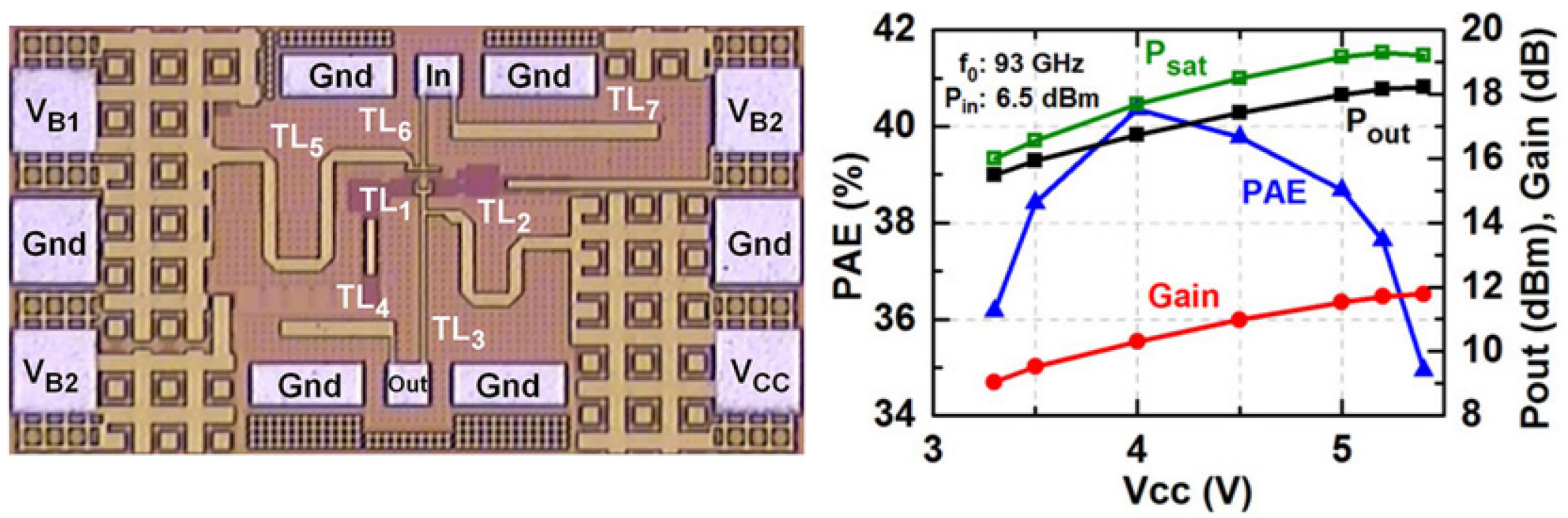

Fig. 13. Bi-CMOS W-band class-E MMIC photo and measured performance [21].

\section{Class-E PAs for High PAPR Signal Transmitters}

Ideal class-E equations detailed in, e.g. [16,22], show that the output power across a fixed load is proportional to the square of the drain (collector) voltage:

$$
P_{\text {OUT }}=0.5 R_{E}\left(1.86 \pi \omega C_{O U T}\right)^{2} V_{D D}^{2}
$$

which in turn implies that class-E PAs are very well suited to envelope tracking for efficiency improvement when the signal has a high peak-to-average ratio [33]. Tracking using a class-E PA and a class-E dc-dc converter with excellent efficiencies in the 1-GHz range is shown in [34]. The 
linearity of such an envelope-tracked transmitter is analyzed experimentally in [20] at a $10 \mathrm{GHz}$ carrier with a two-tone signal. A two-stage $150-\mathrm{nm} \mathrm{GaN}$ on SiC PA is demonstrated with the output stage designed using ideal class-E equations as a starting point, with a power over $10 \mathrm{~W}$, Gsat $>20 \mathrm{~dB}$ and peak PAE $>60 \%$ [19] where the efficiency remains above $50 \%$ at $10 \mathrm{~dB}$ back-off. This PA was specifically designed for supply modulation, i.e. to be stable with minimal capacitance in the drain bias line, enabling broadband signal transmission through the bias network. The measured efficiency curves are shown in Fig.14. Another method for increasing efficiency for high PAPR signals is outphasing, and it has been shown that class-E PAs lend themselves easily to a non-isolated (Chireix) architecture [7], [35-37].
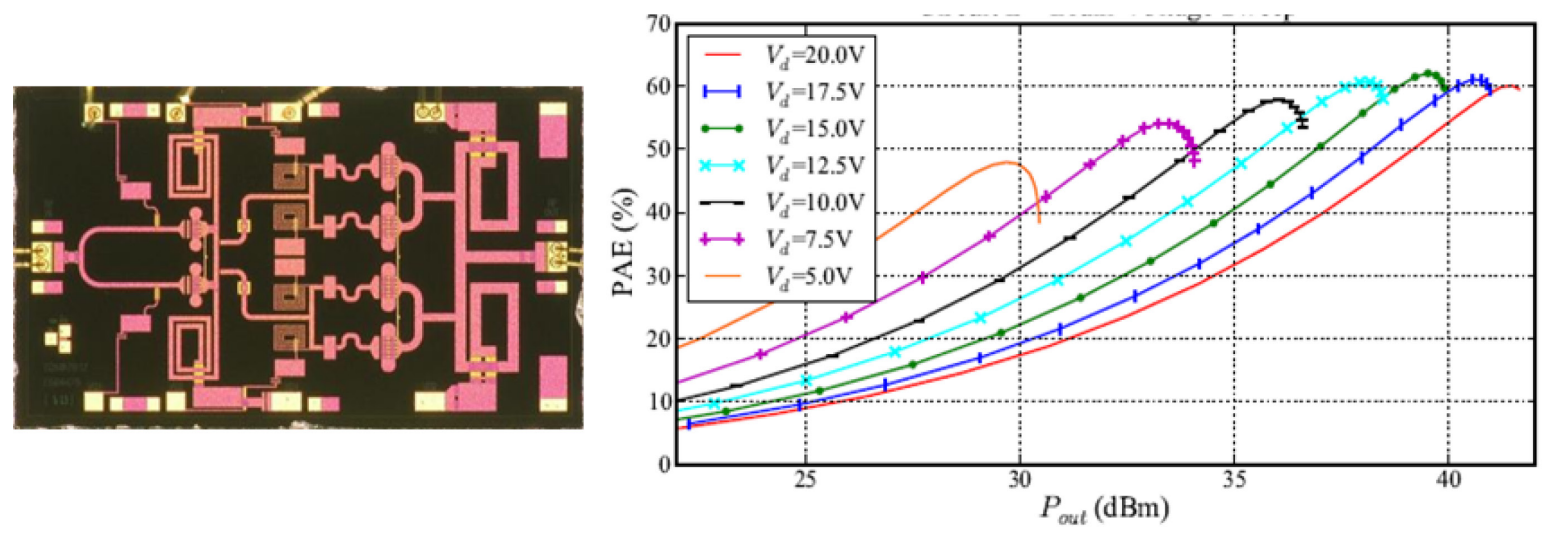

Fig. 14. 10-GHz class-E MMIC PA for supply modulation [19]. The die is $3.8 \mathrm{~mm}$ by $2.3 \mathrm{~mm}$, implemented in a 150-nm gate GaN-on-SiC process by Qorvo. The measured PAE vs. Vdd shows high efficiency up to $10 \mathrm{~dB}$ backoff, with a peak output power of $12 \mathrm{~W}$ and saturated gain over $20 \mathrm{~dB}$ [19].

The class-E PA is classically a tuned topology, which in practice has about $10 \%$ bandwidth over which the frequency, power and PAE remain close to the maximum. Extending the bandwidth of class-E PAs by matching circuit design is investigated in e.g. [38-40]. In [38], over $80 \%$ efficiency is obtained in a low-power class-E PAE from 1.7-2.7 GHz by input matching that includes secondharmonic optimization. In [39], the PAE exceeds $63 \%$ over the $0.9-2.2 \mathrm{GHz}$ band with $3-\mathrm{dB}$ variation in output power. In [40], single-ended and differential matching networks are investigated to obtain a 1.7-2.2 GHz operational bandwidth of a class-E PA implemented in 90$\mathrm{nm}$ CMOS operating in sub-optimal mode with efficiency over $42 \%$ and power above $25 \mathrm{dBm}$. 


\section{CONCLUSIONS}

Other diverse aspects of class-E microwave circuits include oscillators, frequency multipliers, rectifiers and dc-dc converters. The important issue of class-E amplifier stability is examined in [41], while [42] discusses effects of parameter tolerances on class-E behavior. While rectifiers and dc-dc converters are a topic of a separate publication [43], Figs.15 and 16 show examples of microwave frequency class-E oscillators $[44,45]$ and multipliers [46]. A class-E oscillating ring antenna at $10 \mathrm{GHz}$ uses one mode of the ring as a directional coupler for feedback to a class-E amplifier, and a different mode for radiation, Fig.15. This compact efficient oscillator is a complete Doppler radar, since gate bias controls frequency of oscillation and the oscillator behaves as a selfoscillating mixer. Fig. 16 shows a photo of a hybrid 10.4 to 20.8 class-E frequency doubler, along with time-domain waveforms and measured conversion gain and drain efficiency.
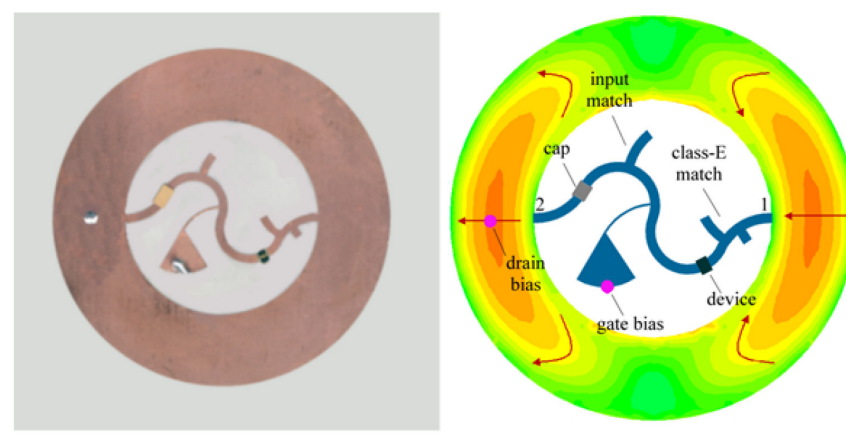

(a)

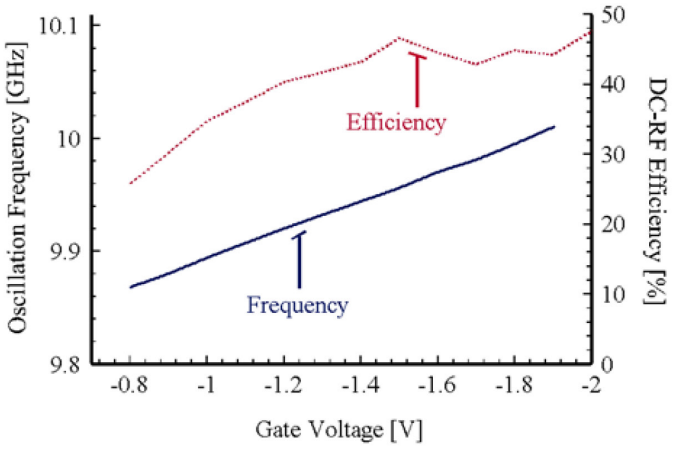

(c)

Fig.15. Class-E active antenna oscillator implemented at $10 \mathrm{GHz}$ with a GaAs MESFET. (a) Photo and (b) circuit layout and current distribution on the antenna-coupler. (c) Measured conversion efficiency and output frequency as a function of gate bias. This integrated active antenna operates as a Doppler sensor since the class-E circuit is a self-oscillating mixer.

Spatial power combining of 16 or more class-E PAs is demonstrated in [47]. Fig. 17 shows the circuit side of an example 10-GHz array, where the 16 PAs are fed with a corporate Wilkinson combiner feed network, while the outputs are combined in free space upon radiation from a 16- 
element in-phase fed patch antenna array. The free-space combining efficiency is estimated to be $80 \%$, which is higher than a 4-level corporate network at $10 \mathrm{GHz}$.

In summary, this paper presents a very brief overview that only gives a glimpse into the vast area of microwave class-E PAs which resulted from Nathan Sokal's pioneering work.
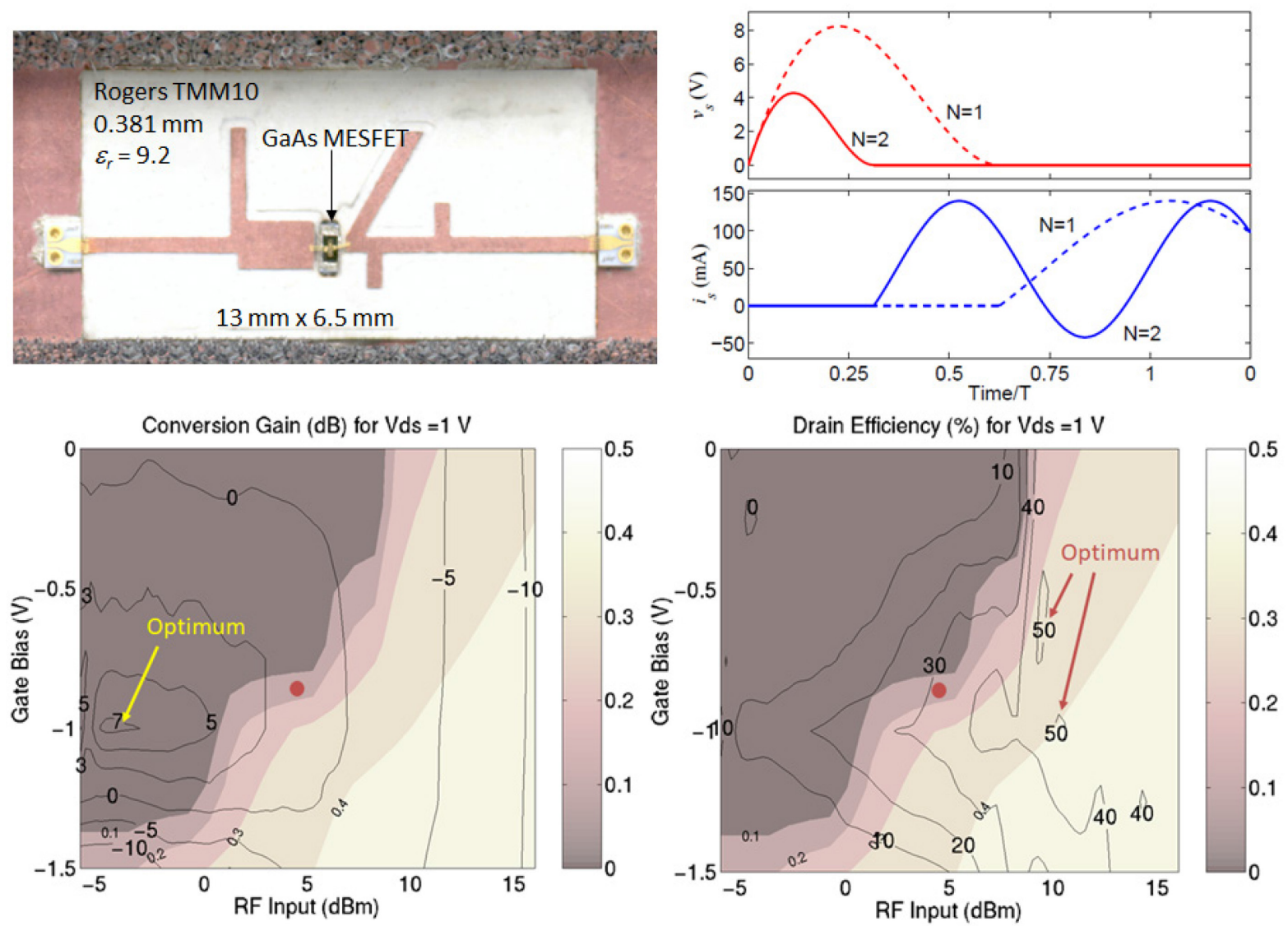

Fig.16. Class-E 10.4 to $20.8 \mathrm{GHz}$ frequency doubler photo (top left) and time-domain waveforms (top right). Measured conversion gain ( $+7 \mathrm{~dB}$ at $-3 \mathrm{dBm}$ input) and efficiency ( $50 \%$ at $10 \mathrm{dBm}$ input) are shown at the bottom [46].

\section{ACKNOWLEDGMENTS}

The authors would like to acknowledge support in part by a Lockheed Martin Endowed Chair at the University of Colorado and in part by the Spanish Ministry of Economy, Industry and Competitiveness (MINECO) through TEC2014-58341-C4-1-R and TEC2017-83343-C4-1-R projects, co-funded with FEDER. 


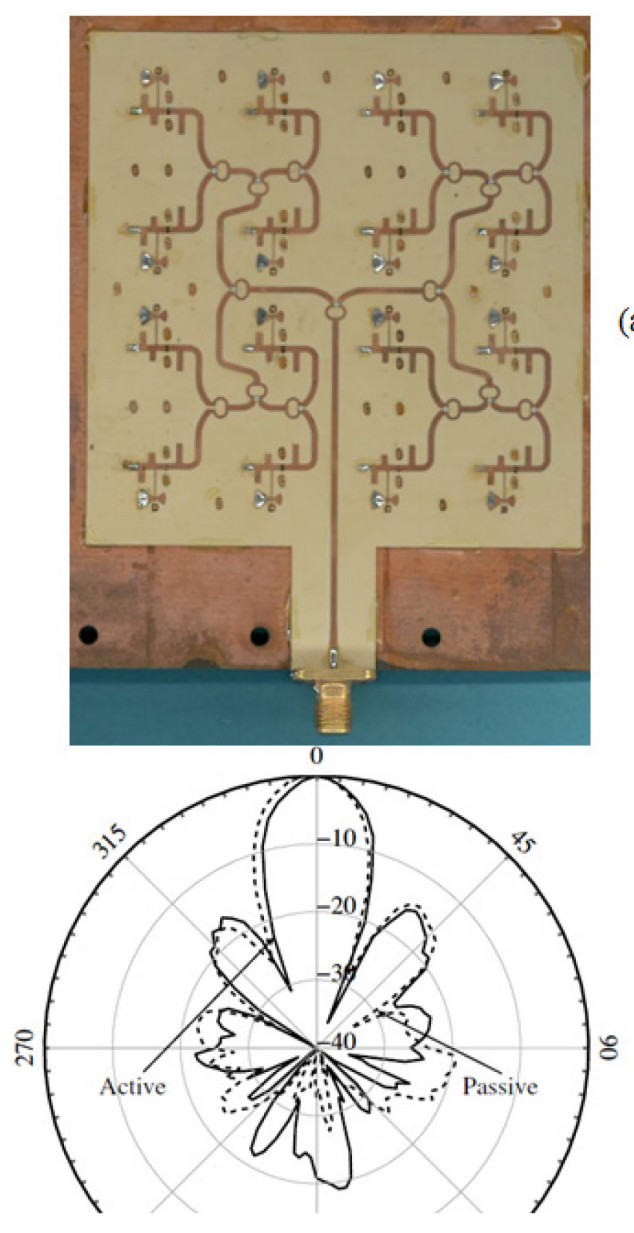

(c)
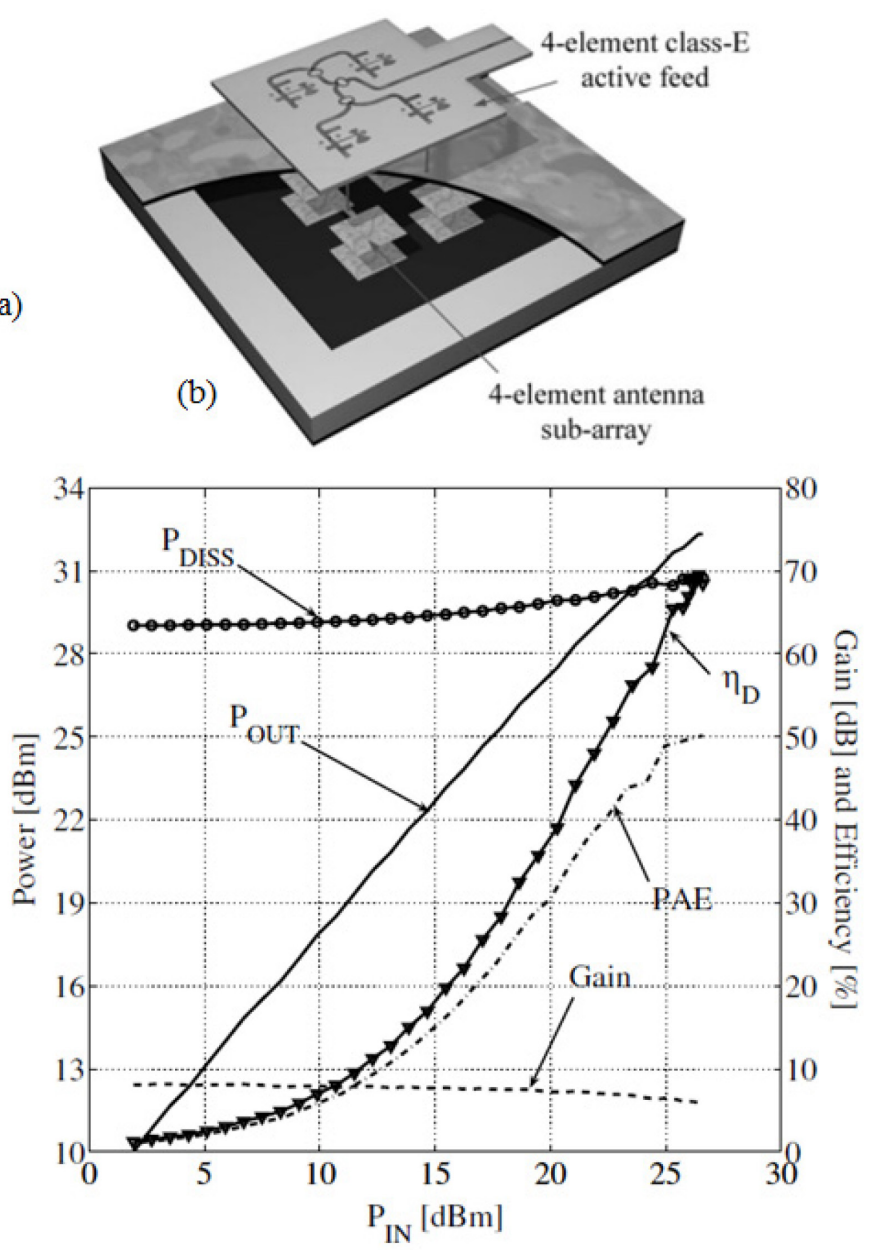

(d)

Fig.17. (a) Photo of corporate input network of a spatial power combiner with class-E PAs at $10 \mathrm{GHz}$ [47].

(b) Sketch of sub-array showing stacked patch antennas. (c) Measured E-plane radiation patters of the passive and active arrays. (d) Measured array performance in a free-space configuration.

\section{REFERENCES}

[1] T. Mader, Z. Popovic, "The transmission-line high-efficiency class-E amplifier," IEEE Guided Wave Lett., vol.5 ,pp. 290-292, Sept.1995.

[2] R. Negra and W. Bächtold, "Lumped-element load-network design for class-E power amplifiers," IEEE Trans. Microwave Theory Techn., vol. 54, no. 6, pp. 2684-2690, Jun. 2006.

[3] J. A. García, R. Marante and M. N. Ruiz, "GaN HEMT class $E^{2}$ resonant topologies for UHF DC/DC power conversion," IEEE Trans. Microwave Theory Techn., vol. 60, no. 12, pp. 4220-4229, Dec. 2012.

[4] R. Beltran and F. H. Raab, "Lumped-element output networks for high-efficiency power amplifiers," IEEE MTT-S Int. Microwave Symp., Anaheim, CA, 2010, pp. 324-327. 
[5] M. Acar, A. J. Annema and B. Nauta, "Analytical design equations for class-E power amplifiers," IEEE Trans. Circuits Syst. I: Regular Papers, vol. 54, no. 12, pp. 2706-2717, Dec. 2007.

[6] M. N. Ruiz, A. L. Benito, J. R. Pérez-Cisneros, P. L. Gilabert, G. Montoro and J. A. García, "Constant-gain envelope tracking in a UHF outphasing transmitter based on continuous-mode classE GaN HEMT PAs," IEEE MTT-S Int. Microwave Symp., San Francisco, CA, 2016, pp. 1-4.

[7] R. Beltran, F. H. Raab and A. Velazquez, "HF outphasing transmitter using class-E power amplifiers," IEEE MTT-S Int. Microwave Symp., Boston, MA, 2009, pp. 757-760.

[8] D. A. Calvillo-Cortes, M. P. van der Heijden, M. Acar, M. de Langen, R. Wesson, F. van Rijs and L. C. N. de Vreede, “A package-integrated Chireix outphasing RF switch-mode high-power amplifier," IEEE Trans. Microwave Theory Tech., vol. 61, no. 10, pp. 3721-3732, Oct. 2013.

[9] D. Vegas, F. Moreno, M. N. Ruiz and J.A. García, "Efficient class-E power amplifier for variable load operation," Workshop on Integrated Nonlinear Microwave and Millimetre-Wave Circuits, Graz, April 2017, pp. 1-4.

[10] Z. Popović and J. A. García, "Microwave class-E power amplifiers," IEEE MTT-S Int. Microwave Symp., Honololu, HI, 2017, pp. 1323-1326.

[11] N. D. Lopez, J. Hoversten, M. Poulton and Z. Popovic, "A 65-W high-efficiency UHF GaN power amplifier," 2008 IEEE MTT-S International Microwave Symposium Digest, Atlanta, GA, 2008, pp. 65-68.

[12] Nestor Lopez, PhD Dissertation, University of Colorado, Boulder, 2008.

[13] P. Colantonio et al., "High frequency class E design methodologies," European GaAs/Semiconductor Application Symp., GAAS 2005, Paris, 2005, pp. 329-332.

[14] T. B. Mader, E. W. Bryerton, M. Markovic, M. Forman and Z. Popovic, "Switched-mode highefficiency microwave power amplifiers in a free- space power-combiner array," IEEE Transactions on Microwave Theory and Techniques, vol. 46, no. 10, pp. 1391-1398, Oct 1998.

[15] R. Tayrani, "A monolithic X-band class-E power amplifier, $23^{\text {rd }}$ IEEE GaAs IC Symp Digest 2001, Baltimore, MD, USA, 2001, pp. 205-208.

[16] S. Pajic, N. Wang, P. Watson, T. Quach, Z. Popovic, "X-band two-stage high-efficiency switchedmode power amplifiers," IEEE Trans. Microwave Theory Techn., vol. 53, no. 9, pp. 2899-2907, Sept. 2005.

[17] Tayrani, Reza. "Two stage microwave Class E power amplifier." U.S. Patent No. 7,265,619. 4 Sep. 2007.

[18] P. J. Bell, Z. Popovic and C. W. Dyck, "MEMS-switched class-A-to-E reconfigurable power amplifier," 2006 IEEE Radio and Wireless Symposium, 2006, pp. 243-246. 
[19] S. Schafer, M. Litchfield, A. Zai, Z. Popovíc and C. Campbell, "X-band MMIC GaN power amplifiers designed for high-efficiency supply-modulated transmitters," 2013 IEEE MTT-S International Microwave Symposium Digest (MTT), Seattle, WA, 2013, pp. 1-3.

[20] N. Wang, X. Peng, V. Yousefzadeh, D. Maksimovic, S. Pajic and Z. Popovic, "Linearity of X-band class-E power amplifiers in EER operation," IEEE Transactions on Microwave Theory and Techniques, vol. 53, no. 3, pp. 1096-1102, March 2005.

[21] P. Song, M. Oakley, A. C. Ulusoy, M. Kaynak, B. Tillack, G. Sadowy, J. Cressler, "A Class-E Tuned W-Band SiGe Power Amplifier With 40.4\% Power-Added Efficiency at $93 \mathrm{GHz}$," in IEEE Microwave and Wireless Components Letters, vol. 25, no. 10, pp. 663-665, Oct. 2015.

[22] F. H. Raab, "Class-E, class-C, and class-F power amplifiers based upon a finite number of harmonics," IEEE Trans. Microwave Theory Techn., vol. 49, no. 8, pp. 1462-1468, Aug. 2001.

[23] M. K. Kazimierczuk and X. T. Bui, "Class-E amplifier with an inductive impedance Inverter," IEEE Trans. Industrial Elect., vol. 37, no. 2, pp. 160-166, April 1990.

[24] D. Y. C. Lie et al., "Highly Efficient Monolithic Class E SiGe Power Amplifier Design at 900 and 2400 MHz," in IEEE Transactions on Circuits and Systems I: Regular Papers, vol. 56, pp. 14551466, July 2009.

[25] R. Brama, L. Larcher, A. Mazzanti and F. Svelto, "A 30.5 dBm 48\% PAE CMOS Class-E PA With Integrated Balun for RF Applications," in IEEE Journal of Solid-State Circuits, vol. 43, no. 8, pp. 1755-1762, Aug. 2008.

[26] J. S. Walling et al., "A Class-E PA With Pulse-Width and Pulse-Position Modulation in $65 \mathrm{~nm}$ CMOS,” in IEEE Journal of Solid-State Circuits, vol. 44, no. 6, pp. 1668-1678, June 2009.

[27] J. S. Walling, S. S. Taylor and D. J. Allstot, “A Class-G Supply Modulator and Class-E PA in 130 nm CMOS,” in IEEE Journal of Solid-State Circuits, vol. 44, no. 9, pp. 2339-2347, Sept. 2009.

[28] J. Chen, R. Bhat and H. Krishnaswamy, "A Compact Fully Integrated High-Efficiency 5GHz Stacked Class-E PA in 65nm CMOS Based on Transformer-Based Charging Acceleration," 2012 IEEE Compound Semiconductor Integrated Circuit Symposium (CSICS), La Jolla, CA, 2012, pp. 1-4.

[29] Y. Yamashita, D. Kanemoto, H. Kanaya, R. K. Pokharel and K. Yoshida, "A CMOS class-E power amplifier of 40-\% PAE at $5 \mathrm{GHz}$ for constant envelope modulation system," 2013 IEEE 13th Topical Meeting on Silicon Monolithic Integrated Circuits in RF Systems, Austin, TX, 2013, pp. 66-68.

[30] D. B. Santana, H. Klimach, E. Fabris and S. Bampi, "A power controlled RF CMOS class-E PA with 43\% maximum efficiency in $2.2 \mathrm{GHz}, " 2015$ IEEE International Conference on Electronics, Circuits, and Systems (ICECS), Cairo, 2015, pp. 97-100. 
[31] H. Alsuraisry, M. H. Wu, P. S. Huang, J. H. Tsai and T. W. Huang, "5.3 GHz 42\% PAE class-E power amplifier with $532 \mathrm{~mW} / \mathrm{mm}^{2}$ power area density in $180 \mathrm{~nm}$ CMOS process," in Electronics Letters, vol. 52, no. 15, pp. 1338-1340, 7212016.

[32] M. Kreißig, R. Kostack, J. Pliva, R. Paulo and F. Ellinger, "A fully integrated $2.6 \mathrm{GHz}$ cascode classE PA in $0.25 \mu \mathrm{m}$ CMOS employing new bias network for stacked transistors," 2016 IEEE MTT-S Latin America Microwave Conference (LAMC), Puerto Vallarta, 2016, pp. 1-3.

[33] 25 M. Weiss, F. Raab, Z. Popovic, "Linearity of X-band class-F power amplifiers in high-efficiency transmitters," IEEE Trans. Microwave Theory Techn., vol. 49, no. 6, pp. 1174-1179, Jun 2001.

[34] J. A. García, R. Marante, M. N. Ruiz and G. Hernández, "A 1 GHz frequency-controlled class $\mathrm{E}^{2} \mathrm{DC} / \mathrm{DC}$ converter for efficiently handling wideband signal envelopes," 2013 IEEE MTT-S International Microwave Symposium Digest (MTT), Seattle, WA, 2013, pp. 1-4.

[35] M. N. Ruiz, A. L. Benito, J. R. Pérez-Cisneros, P. L. Gilabert, G. Montoro and J. A. García, "Constant-gain envelope tracking in a UHF outphasing transmitter based on continuous-mode classE GaN HEMT PAs," 2016 IEEE MTT-S Intern. Microwave Symp. San Francisco, CA.

[36] D. A. Calvillo-Cortes et al., "A Package-Integrated Chireix Outphasing RF Switch-Mode HighPower Amplifier," in IEEE Transactions on Microwave Theory and Techniques, no. 10, pp. 37213732, Oct. 2013.

[37] A. Ghahremani, A. J. Annema and B. Nauta, "A 20dBm outphasing class-E PA with high efficiency at power back-off in 65nm CMOS technology," 2017 IEEE Radio Frequency Integrated Circuits Symposium (RFIC), Honolulu, HI, 2017, pp. 340-343.

[38] V. Chaudhary and I. S. Rao, "A novel 2GHz highly efficiency improved class-E Power Amplifier for Base stations," 2015 Intern. Conf. Comm. and Signal Processing (ICCSP), Melmaruvathur, 2015, pp. 0940-0944.

[39] K. Chen and D. Peroulis, "Design of Highly Efficient Broadband Class-E Power Amplifier Using Synthesized Low-Pass Matching Networks," IEEE Trans. Microwave Theory Techn., pp. 3162-3173, Dec. 2011.

[40] M. D. Wei, D. Kalim, D. Erguvan, S. F. Chang and R. Negra, "Investigation of Wideband Load Transformation Networks for Class-E Switching-Mode Power Amplifiers," IEEE Trans. Microwave Theory and Techniques, vol. 60, no. 6, pp. 1916-1927, June 2012.

[41] J. de Cos, A. Suárez and J. A. García, "Hysteresis and Oscillation in High-Efficiency Power Amplifiers," IEEE Transactions on Microwave Theory and Techniques, vol. 63, no. 12, pp. 42844296, Dec. 2015.

[42] F. H. Raab, "Effects of circuit variations on the class E tuned power amplifier," IEEE J. Solid-State Circuits, no. 2, pp. 239-247, Apr 1978. 
[43] J. A. García and Z. Popović, "Class-E rectifiers and power converters," 2017 IEEE MTT-S International Microwave Symposium (IMS), Honololu, HI, 2017, pp. 1327-1330.

[44] E. W. Bryerton, W. A. Shiroma and Z. B. Popovic, "A 5-GHz high-efficiency class-E oscillator," in IEEE Microwave and Guided Wave Letters, vol. 6, no. 12, pp. 441-443, Dec 1996.

[45] J. A. Hagerty and Z. Popovic, "A $10 \mathrm{GHz}$ active annular ring antenna," IEEE Antennas and Propagation Society International Symposium (IEEE Cat. No.02CH37313), 2002, pp. 284-287

[46] Manoja Wiess, PhD Dissertation, University of Colorado, Boulder, 2001.

[47] S. Pajic, Z. Popovic, "An efficient X-band 16-element spatial combiner of switched-mode power amplifiers," IEEE Trans. Microwave Theory Techn., pp. 1863-1870, July 2003. 